\title{
Formação docente para o Ensino Secundário e os Cursos da CADES em Campo Grande, Mato Grosso (1956 a 1959)
}

Teaching training for secondary education and CADES classes in Campo Grande, Mato Grosso (1956 to 1959)

\author{
Stella Sanches de Oliveira Silva \\ Orcid: https://orcid.org/0000-0001-7643-8015 \\ Universidade Federal de Mato Grosso do Sul, Campo Grande, Brasil, \\ stella.oliveira@ufms.br \\ Marcela Oliveira da Silva \\ Orcid: https://orcid.org/0000-0002-3947-7514 \\ Universidade Federal de Mato Grosso do Sul, Campo Grande, Brasil, \\ oliveira.marcela@ufms.br
}

Received on 21/12/2020 - Approved on 28/12/0000

\section{Resumo}

Este trabalho tem o objetivo de apurar a configuração docente de uma escola de ensino secundário, Colégio Estadual Campo-grandense, na cidade de Campo Grande, bem como o desenvolvimento dos cursos e aplicação de exames da Campanha de Aperfeiçoamento e Difusão do Ensino Secundário (CADES) que ali ocorreram, observando a formação docente secundarista como objeto. $O$ procedimento investigativo foi subsidiado pelas contribuições de Jörn Rüsen. Para tanto, foram selecionadas fontes documentais (1953-1959) e dissertações de mestrado entre 2005 e 2013. O processo investigativo apontou características que revelaram tanto a configuração da formação dos professores como também as formas de contratação desses profissionais.

Palavras-chave: CADES. Ensino Secundário. Formação de Professores.

\section{Abstract}

This work aims to determine the teaching configuration of a secondary school, Colégio Estadual Campo-grandense, in the city of Campo Grande, as well as the development of courses and application of exams of the Campaign for Improvement and Dissemination of Secondary Education (CADES) that occurred there, observing 
secondary education as an object. The investigative procedure was subsidized by the contributions of Jörn Rüsen. To this end, documentary sources (1953-1959) and master's dissertations were selected between 2005 and 2013. The investigative process pointed out characteristics that revealed both the configuration of teacher training and the hiring ways for these professionals.

Keywords: CADES. Secondary Education. Teacher Training.

\section{Introdução}

A formação docente se tornou uma pauta proeminente na década de $1931 \mathrm{com}$ a Reforma Francisco Campos (Decreto no 19.890, de 18 de abril) que impôs a obrigatoriedade de uma formação superior para professores pelas Faculdades de Educação, Ciências e Letras e seu registro oficial no Departamento Nacional de Ensino para lecionar no ensino secundário (Brasil, 1931).

A relação entre a crescente demanda que acessava a etapa secundária e a não suficiência dos agentes para atendê-la, somadas à imposição da lei, sugeria ações emergenciais pelo poder público. A opção que se moldou foi propor ao professorado uma mínima regularização, nesse intuito foi criado o Exame de Suficiência pelo Decreto no. 8.777, de 22 de janeiro de 1946. O instrumento foi concebido em forma de prova e, uma vez que, o postulante alcançasse a nota maior ou igual a seis, garantiria seu registro oficial e autorização para lecionar.

Não obstante, a falta de preparo e conhecimento dos candidatos resultava em baixo índice de aprovação. Em 1953, com objetivo de elevar a qualidade do ensino, foi criada a Campanha de Aperfeiçoamento e Expansão do Ensino Secundário pelo Decreto no 34.638, de 17 de novembro. Dentre seus pressupostos estava o encargo de "promover a realização de cursos e estágios de especialização e aperfeiçoamento para professôres, técnicos e administradores de estabelecimentos de ensino secundário". (Brasil, 1953). Os cursos ocorriam geralmente de maneira concentrada nos meses de janeiro, antes do período letivo, sucedidos pela aplicação dos exames.

Na prática de uma pesquisa ${ }^{1}$ mais ampla empreendida pelas pesquisadoras sobre a expansão do ensino secundário no sul de Mato Grosso, verificou-se que, entre as décadas de 1950 e 1960, houve uma nítida expansão do ensino secundário demarcada sobretudo pelo aumento do número de estabelecimentos e de matrículas. Ademais, no interior do movimento de expansão, veio a exigência por professores com formação.

A partir dos passos consolidados da pesquisa, foi possível a definição do objeto de estudo ora apresentado, a formação docente para o ensino secundário. Para então indagarmos: como e onde os professores conseguiam se formar para lecionar nessa etapa de ensino? Ou eles nem eram formados?

Tendo em mãos dissertações sobre a história de disciplinas escolares de uma escola secundária de Campo Grande, foi-se descoberta a realização de alguns cursos e exames da CADES na cidade. A existência de uma campanha, como o caso da CADES, para regularizar a situação de professores de ensino secundário sem formação específica, conduziu à outra indagação: Como foram as atividades da CADES? Quais disciplinas esses professores lecionavam?

Tomamos como objetivo apurar a configuração docente da escola secundária onde ocorreram os cursos e aplicação de exames da CADES na cidade de Campo 
Grande, o Colégio Estadual Campo-grandense, e analisar o desenvolvimento da Campanha de Aperfeiçoamento e Difusão do Ensino Secundário.

O recorte temporal estabelecido, de 1956 a 1959, justifica-se por ter sido o período em que foram realizadas as atividades da CADES, na cidade de Campo Grande, à época ainda parte do estado de Mato Grosso uno.

O procedimento investigativo foi subsidiado pelas contribuições do historiador alemão Jörn Rüsen. Rüsen (2007) propôs uma concepção da História como ciência, abordando aspectos sobre o método e a pesquisa históricos, além de um entendimento sobre o tratamento das fontes e a narrativa histórica. Para o historiador, "pesquisa histórica é um processo cognitivo, no qual os dados das fontes são apreendidos e elaborados para concretizar ou modificar empiricamente perspectivas (teóricas) referentes ao passado humano". (Rüsen, 2007, p. 104).

De modo que para o percurso desta pesquisa, tomou-se a investigação histórica como um ofício de historiador, por meio da qual foram estabelecidas operações reunindo um corpus material, para que a empiria do passado e do presente nas fontes pudessem ser assimiladas.

Para tanto, utilizou-se o acervo de documentos da Escola Estadual Maria Constança Barros Machado, antigo Colégio Estadual Campo-grandense, reunido e disponibilizado em quatro DVDs produzidos por Pessanha e Assis (2011). A análise se ateve aos documentos que correspondem aos livros de registro referentes à admissão e posse de professores e inscrição tanto para a prova de suficiência quanto para os cursos da CADES (1953 - 1959).

Paralelamente à seleção de fontes documentais, foram selecionadas seis dissertações produzidas entre 2005 e 2013 que abordam os percursos de professores participantes dos cursos da CADES realizados no Colégio Estadual Campograndense.

Este texto está organizado em três seções: 1. A formação docente do ensino secundário no Brasil entre 1930 e 1950; 2. Entre Militares e normalistas: a infinidade de profissões do corpo docente do Colégio Estadual; 3. Enfim, uma solução? Os cursos da CADES em Campo Grande.

\section{A formação docente para o ensino secundário no Brasil entre 1930 e 1950}

As preocupações voltadas à formação docente para atender o ensino secundário no Brasil se tornaram mais evidentes juntamente às reformas educacionais efetuadas na terceira década do século XX. Tanto a formação superior na área da licenciatura como a própria organização da educação, como se conhece hoje, não possuíam uma estrutura clara e sistematizada. Miranda (2019) explica:

[...] que até a década de 1930 não havia legislação específica acerca da formação de professores para essa modalidade de ensino. É com a Reforma Francisco Campos, de 1931, que são criados os primeiros cursos superiores de formação de secundários a serem oferecidos por Faculdades de Filosofia, Ciências e Letras (FFCL), sendo a primeira delas integrante da Universidade de São Paulo (USP), criada em 1934. (p.72). 
A falta de diretrizes que organizassem um curso superior ao professorado secundarista, destacando inclusive a criação de faculdades no campo da licenciatura somente a partir da 6ª reforma da Primeira República.

A contar pela grande quantidade de professores que não possuíam formação específica superior na área de educação, é possível presumir que os não diplomados poderiam ser a maioria. As primeiras décadas do século passado não contavam com uma distribuição de instituições superiores além dos centros urbanos reconhecidos como importantes economicamente.

Os professores eram "pessoas que lecionavam no ensino primário e que haviam se destacado neste nível de ensino ou, muitas vezes, profissionais liberais que não conseguiam se [despontar] financeiramente em suas profissões, almejando um complemento no orçamento financeiro". (Ferreira; Santos, 2007, p. 73). Além de serem poucos os professores que atuavam nas escolas secundárias Brasileiras que tinham formação de nível superior, "esses eram formados em Faculdades de Filosofia, nas escolas politécnicas ou eram oriundos de outros cursos" (Baraldi, 2016, p. 34).

No raiar da década de 1940, novas reformas educacionais foram propostas, dessa vez, como parte de um projeto mais amplo e orgânico que se consubstanciou em Leis Orgânicas contemplando os ensinos industrial, secundário, comercial, agrícola e normal.

As reformas expressaram a necessidade da formação superior do magistério atuante no ensino secundário, porém o que se apresentava na educação tanto primária quanto secundária, especificamente nas cidades mais afastadas localizadas nos interiores do Brasil, era a presença de profissionais diversos e um mínimo, ou nenhum, de formandos nas faculdades de Filosofia e Letras ao passo que aumentava a demanda pelo ensino primário e secundário.

$\mathrm{Na}$ década seguinte, foram instauradas campanhas nacionais no campo educacional como a Campanha do Livro Didático e Manuais de Ensino (CALDEME), Campanha de Levantamentos e Inquéritos para o Ensino Médio e Elementar (CILEME) e a Campanha de Aperfeiçoamento e Difusão do Ensino Secundário (CADES), todas exercidas no período de 1956 a 1960.

O modo de operação escolhido pelas campanhas foi a política de publicações tanto de livros didáticos quanto de revistas especializadas. Especialmente a CALDEME e CILEME objetivaram ser instrumentos de ampliação dos conhecimentos sobre os conteúdos do currículo escolar e da realidade do ensino nacional. E quanto a CADES?

A Campanha de Aperfeiçoamento e Difusão do Ensino Secundário (CADES), Decreto no 34.638, de 17 de novembro de 1953, consistiu em uma política pública emergencial para capacitar e adequar os profissionais sem licenciatura a fim de alcançarem o registro e autorização oficial para lecionar por meio de aprovação no exame de suficiência, em todo país, munidos de conhecimento específico e didático. A Campanha teve como público-alvo o corpo docente no ensino secundário, etapa sequencial ao ensino primário. Um breve resumo de suas ações é descrito por Backes e Gaertner (2007):

Dos meados da década de 1950 até o ano de 1971, a CADES prestou serviços à educação Brasileira gerenciando a realização de cursos de formação para professores do ensino secundário, jornadas de diretores, simpósios de 
orientação educacional, encontros de inspetores do ensino secundário, cursos para secretários de estabelecimentos de ensino. (p. 22).

Porém, se até aquele momento não parecia haver a necessidade de formação superior de professores, o que motivou a instituição tanto da Campanha quanto dos Exames? A resposta se encontra relacionada ao momento político-social do país. Fonseca (2003) dá indícios para a compreensão do questionamento:

Ao longo de toda a década de 1940 e 1950, o crescimento do ensino primário e os processos de urbanização/industrialização trouxeram consigo uma situação nova para o panorama educacional secundário Brasileiro: a expansão do ensino. O aumento do número de estabelecimentos de ensino e da população escolarizada, juntamente as leis contra o trabalho infantil e a migração para as cidades levaram a uma expansão "quantitativa" do número de matrículas e a maior pressão por vagas nas escolas secundárias. Conseqüentemente (sic), surge a necessidade de mais professores. (p.1).

A ideia de transformação urbana e crescimento industrial aliada ao aumento da demanda por educação observada por Fonseca (2003) é corroborada por Pinto (2008, p. 151): "na década 1942-1952, a expansão do ensino secundário foi de $210 \%$ no primeiro ciclo e de $436 \%$ no segundo ciclo no que se refere a matrículas. Em relação ao número de unidades, essa expansão foi de $1.084 \%$ e $498 \%$, respectivamente".

A procura pelo ensino secundário também pode ser atribuída, segundo Pinto (2008, p. 151), a uma combinação de fatores que impulsionaram a elevação de interesse da população. Primeiro, a intenção do povo de ascender socialmente pela via da formação escolar secundária e posterior admissão ao Ensino Superior somada às mudanças da Reforma Capanema, e, por fim, o ponto de partida que a Constituição de 1937 estimulou quando designou o ensino profissionalizante às camadas populares.

Tais informações reforçam o entendimento da necessidade de aumentar o contingente de professores no Brasil. Na ausência de profissionais devidamente formados para atender a demanda, de maneira provisória, foi autorizada a admissão de outros profissionais e o recrutamento de alunos que expressavam um desempenho significativo no ensino secundário. Médicos, advogados, militares, padres, imigrantes e normalistas eram alguns exemplos da bagagem formativa dos professores de ensino secundário no Brasil.

\section{Entre Militares e normalistas: a infinidade de profissões do corpo docente do Colégio Estadual}

A educação escolar secundária no sul de Mato Grosso pode ser explorada paralelamente à descrição de condicionantes políticos e econômicos ocorridos principalmente no eixo Corumbá/Campo Grande. Para Brito (2001): 
É importante frisar que essas transformações não estavam ocorrendo de forma isolada, sendo, contudo, parte do processo de mudanças pelas quais passavam Estado e sociedade, no Brasil, naquele período; assim como não tiveram os anos 30 como marco inicial, sendo parte de um processo de mudanças que se vinha dando a partir da segunda metade dos anos 20 , em Mato Grosso e em todo o país. (p. 56).

As mudanças enfatizadas por Brito são retratadas, por exemplo, por adventos entendidos como marcadores de modernização, foram eles: o Porto de Corumbá (1853) e sua importância nacional no transporte e comércio pela via fluvial, a chegada do telégrafo (1904) na cidade de Campo Grande, a construção da Estrada de Ferro Noroeste Brasil (1907) e a transferência do Comando da Circunscrição Militar para a Campo Grande (1921).

Conforme as informações relacionadas por Brito e Oliveira (2019), entre os anos de 1916 e 1941, havia no sul de Mato Grosso oito estabelecimentos ${ }^{2}$ de ensino secundário. Dentre eles, um público e sete privados. No que se refere a Campo Grande são registrados quatro estabelecimentos, sendo três privados e um de caráter público. Entre 1942 e 1959, o sul do estado passou a ter mais nove instituições ${ }^{3}$. Nesse ínterim, a proporção entre espaços públicos e privados diminuiu. Esclarece-se que seis deles eram públicos e três privados.

Na década de 1930 é que Campo Grande, pelo Decreto ํo 229, de 27 de dezembro de 1938, ganhou um espaço público de ensino secundário, o Liceu Campograndense, mais tarde, em 1954, passando a ser denominado Colégio Estadual Campo-grandense.

As leituras das seis dissertações revelaram características que corroboram com o aprofundamento sobre as condições profissionais do corpo docente secundário. Para tanto, a descrição do Colégio Estadual, sua origem e história se fazem necessárias.

O Colégio Estadual Campo-grandense ao longo de sua história passou por mudanças tanto de nomenclatura quanto de espaço e endereço. Sua primeira localização foi anexa ao prédio do Grupo Escolar Joaquim Murtinho. Seu nome foi alterado para Ginásio Campograndense, em 1942, pelo decreto oo 101 de 27 de maio, orientado pela normativa da Reforma Capanema que determinava que as escolas não submetidas à inspeção permanente utilizassem o prefixo ginásio.

A equiparação ao Colégio Pedro II, Rio de Janeiro, exigência legal, foi autorizada em 1944, no dia 28 de agosto, pela circular do DES no 5 . Em 1953, a instalação do $2^{\circ}$ Ciclo secundário foi autorizada pelo Ministério da Educação e uma nova alteração de nome para Colégio Estadual de Campo Grande.

Em 25 de setembro do ano seguinte, o Colégio ganhou uma sede própria, concebida pelo arquiteto Oscar Niemeyer, no bairro Amambaí, embora, que de fato, o projeto original havia sido destinado ao Ginásio Maria Leite, em Corumbá, cidade ao sul de Mato Grosso com fronteira com Bolívia e Paraguai. A escola passou ainda por mais mudanças de nomenclatura, em 1958, para Colégio Estadual Campo-grandense (Portaria oㅜ 1.058, de 21 de novembro), em 1971, para Colégio Estadual Maria Constança Barros Machado (Lei oㅜ 3.027 de 28 de abril), em 1976, para Escola Estadual de $1^{\circ}$ e $2^{\circ}$ graus Maria Constança Barros Machado, em 1976 (Decreto ํo. 769 de 26 de outubro), e atualmente, desde 1996, chama-se Escola Estadual Maria Constança Barros Machado. 
Ribeiro (2013) sustenta que um dos indicadores mais marcantes em relação às tais práticas era a atuação docente. Em suas considerações é possível salientar que o desempenho dos professores era medido por dois fatores "a dedicação em ensinar e o capital simbólico, revelado pelo orgulho" de pertencer ao Colégio (Ribeiro, 2013, p. 85), haja vista que o quadro docente era constantemente solicitado para palestrar à sociedade e representar a instituição em solenidades.

Ribeiro (2013, p.86) relata o que foi dito por uma ex-aluna: "[...] eu acho que eles eram exigentes, exigência! [...] Eles eram muito competentes, um espelho". Em outro trecho, a ex-aluna expôs sua insatisfação com desempenho do professor de Inglês:

Eu tive um professor de Inglês [...] ele era péssimo [...] não tinha uma boa formação de Inglês e ensinava a gente errado. [...] Ele nunca tinha ido para os Estados Unidos, a formação dele era fraca, a gente não ia muito além, porque ele era muito limitado, não tinha professor naquela época. (Ribeiro, 2013, p.87).

Outro aluno, em suas considerações, revelou elementos que se colocam simétricos à hipótese sobre a condição da formação docente para o ensino secundário. Segundo ele:

[...] nós tivemos professores de Português que eram advogados, o José Fragelli, que foi governador, ele foi professor de Português e ele foi um excelente professor. Depois ele foi para o lado da política, e nem advogado ele era mais, ficou só na política. O João Pereira era advogado e foi secretário de Justiça. Na Universidade Federal, que antigamente era estadual, ele dava aula no curso de Odontologia. (Ribeiro, 2013, p. 88).

Registros oficiais do Colégio Estadual revelam que os professores advinham de outras áreas profissionais e até mesmo não possuíam nenhuma formação superior, como inclusive informou o levantamento de professores da disciplina de Francês, entre 1942 e 1962. (Oliveira, 2009).

Nele, a autora explicita que dentre os doze professores da instituição ${ }^{4}$ : havia um médico, um servidor público estadual aposentado, três normalistas, três formadas em Línguas Neolatinas, um certificado pelo curso da CADES, um imigrante italiano com habilidade no idioma francês, um sem formação declarada e uma com curso de francês.

Utilizando-se de um maior detalhamento, Oliveira (2009) descreve aspectos relacionados à admissão, exoneração e exercício dos professores supracitados. Reitera-se que todos os docentes atuaram sobre a regência tanto da Reforma Francisco Campos, primeira a exigir formação superior para lecionar no ensino secundário, quanto dos cursos da CADES, inclusive àquela altura já realizados em Campo Grande. Excetuando-se os professores licenciados pela CADES, assim como os formados em Línguas Neolatinas, os demais representavam as práticas extralegais exercidas pela administração.

O médico Nicolau Fragelli, que atuou de 1939 a 1945, não dispunha de registro para lecionar, apesar de ter solicitado o registro no Departamento de Ensino, em 1942. Após sua exoneração, Fragelli foi substituído por João Calixto Bernardes, em 1945, 
funcionário público estadual aposentado, este permanecendo apenas um ano no cargo.

A professora Anna Luiza Prado Bastos, atuou por uma década no ensino de Francês, 1947 a 1957, mesmo sendo normalista. De 1958 até 1959, Alexandre do Espírito Santo assumiu a cadeira de Francês e Português. Sua formação não foi encontrada nos registros (Oliveira, 2009, p. 121). A normalista Therezinha de Oliveira Paulino foi professora por dois anos, de 1960 a 1962, e mesmo não possuindo formação superior, Therezinha havia sido professora de Francês no Ginásio Estadual 2 de julho, em Três Lagoas, em 1955.

Marly Proença Teixeira foi aluna do Colégio Estadual, em 1958, e cursou Línguas Neolatinas por um ano na Universidade do Brasil no Rio de Janeiro, integrando o quadro de professores de Francês em 1960. A professora tinha formação de um curso de francês realizado na Aliança Francesa de Campo Grande. Oliveira (2009) apurou que a professora foi requerida por autorização legal da inspetoria seccional para exercer igualmente a cadeira de Português.

Outro professor de Francês foi Claudio Guiseppe Furlanetto que, entre 1959 e 1960, "por ser italiano e ter aprendido Francês na Europa, pôde ser admitido pelo Colégio Estadual Campo-grandense como professor da disciplina" (Oliveira, 2009, p.122).

O caso da admissão do imigrante italiano pode ser considerado como um desvio à norma para atender as disciplinas do ensino secundário, pois havia no Livro de Registro de Correspondências Recebidas (1945/1951) ordens do Interventor do Estado, Julio Müller, que expressavam a não permissão de estrangeiros como professores. No ano de 1957, no Livro Cadastro Geral de Professores, havia três docentes estrangeiros admitidos: Nagib Raslan (libanês), Carlos Henrique Schrader (alemão) e Giovanni Rocca (italiano). (Oliveira, 2009).

A necessidade da manobra nas orientações legais pode ser justificada, a priori, pela familiaridade e conhecimento em outros idiomas que aqueles possuíam, apesar da ausência de autorização pelo Departamento Nacional de Ensino ou formação superior específica.

A disciplina de Latim, por outro lado, era ministrada por padres, conforme Braga (2005) expôs em sua dissertação por meio de depoimentos de alunos e professores do Colégio Estadual. Ele classificou a década de 1940 como um período complicado para a disciplina, já que tanto os alunos quanto os documentos oficiais relatavam a presença de ex-padres, seminaristas, pastores protestantes entre outros membros de ordem religiosa como grande parte do corpo docente titular do ensino de Latim.

A ex-aluna Cida Bogalho (Braga, 2005, p. 111) relembra a precariedade da disciplina e atribuiu o fato à falta de interesse dos professores em ensinar. Ela revelou ainda que o ensino de Latim era ministrado por "[...] dois ex-padres [e que] não estavam nem um pouco comprometidos com ensinar e ensinar bem. O primeiro, de origem alemã, ele propriamente não dava aula." Outra entrevistada, a ex-professora Maria da Gloria Sá Rosa admitiu que:

[...] havia esse hábito dos professores de latim serem padres por causa do seminário - estudavam 8 horas por dia de latim e em geral eles saíam conhecendo a disciplina, não é?... Acho que a primeira coisa que se exige do professor é competência - é o conhecimento da matéria - depois as técnicas 
didáticas, maneira de comunicação, maneira de transmitir, não é? (Rosa citado por Braga, 2005, p.109).

Entende-se neste excerto que o conhecimento autodidata ou pela atividade exercida se sobrepunha propriamente a uma formação adequada para lecionar.

Braga (2005, p.84) classificou os anos 1950 como os melhores anos do ensino de Latim no Ginásio Estadual devido não propriamente à formação do corpo docente, mas sim, ao entusiasmo e saudosismo presentes nas declarações de ex-alunos. A constatação exposta "trata-se agora de uma visão que atribui valores positivos, em primeiro lugar, ao professor" (Braga, 2005, p.84) e que ainda não correlaciona a formação superior ao desempenho do docente. Creuza, ex-aluna do professor de Latim, chamado Candão, reforça que "estudando o Latim eu aprendi muito da Língua Portuguesa. O meu conhecimento do Português devo muito ao Latim. Suas aulas eram interessantes e prendiam a atenção dos alunos. Dava gosto estudar com o Candão". (Braga, 2005, p.112).

Nas décadas seguintes, mesmo em pleno movimento da CADES pelo país, foi possível encontrar nos registros e depoimentos professores, atuantes em Campo Grande, que não possuíam nenhuma formação exigida, tão pouco eram admitidos conforme a prescrição da lei.

A exemplo, Braga (2005, p.86) ilustra um acontecimento que não parecia ser incomum. Em entrevista, Alzira, ex-aluna e ex-professora do Colégio, menciona a sua admissão como professora no final da década de 1950, mesmo sem a formação superior. Assim ela justifica que "por ter-me destacado como aluna de Latim no ginásio, quando cursava o colegial, em 1959, o diretor obrigou-me, por assim dizer, no impedimento do professor de Latim do ginásio, a assumir essa disciplina como professora no ginásio" (Braga, 2005, p. 111).

Denota-se que a prática de recorrer aos ex-alunos como substitutos e até titulares em disciplinas não parecia ser algo esporádico, tendo em vista que eles eram referendados por Atos e Ofícios por parte do governo e registrados nos documentos do Colégio.

Outros depoimentos de ex-professores do Colégio apurados por Adimari (2005) demonstraram que ser admitido como professor transcendia à formação exigida, passando pelo crivo da indicação de terceiros. Segundo a afirmação do ex-professor de Inglês, Catulo, seu ingresso no quadro funcional do Colégio, em 1967, foi em decorrência da indicação do diretor de outro estabelecimento, Ginásio Estadual de Bela Vista, o advogado Dr. Sidney Pimentel. A ex-professora de Matemática, Elis, afirmou que foi "[...] convidada a dar aula no Colégio Estadual [...], onde lecionou matemática de 1963 a 1976. Ana, ex-professora de Geografia, acrescenta que "[...] era uma honra dar aulas naquela escola, os professores geralmente eram indicados por outras pessoas". (Adimari, 2005, p. 107).

Como colocado, o que ocorria no Francês e no Latim pode ser igualmente verificado em outras três disciplinas: Educação Física, História e Língua Inglesa.

Constituída como prática obrigatória para alunos do sexo masculino pela Reforma Capanema, em 1942, a Educação Física apresentava forte influência militar sobre a origem dos profissionais contratados.

Não apenas a disciplina de Educação Física, mas o próprio Colégio Estadual Campo-grandense abrigava uma condição correspondente à história desta disciplina. Nesse sentido Braga (2006, p.69) discorre que: 
No Colégio Estadual Campo-grandense, em 1954, a característica militarista esteve presente e mais visível na contratação dos professores militares para ministrar a disciplina, do que nas práticas escolares com características militares. Ainda que algumas práticas, tais como fila, desfile, marchas e outras fossem a tônica das aulas.

O autor apresenta dois professores do Colégio Estadual, Alcídio Pimentel e Jairo Alves Fontoura, ambos militares e sem formação superior. Eles lecionaram na escola na década de 1950 e 1960, sempre contando com o apoio da direção escolar e com o prestígio de sua ocupação militar.

$\mathrm{O}$ autor descreve as duas personalidades como diferentes. Alcídio Pimentel se formou na Escola de Educação Física do Exército e "sua história como professor do Maria Constança se confunde com a trajetória do esporte e da Educação Física da cidade" (Braga, 2006, p.69). O professor pertenceu ao Colégio desde 1946. Sua atuação ficou conhecida pelo estímulo ao esporte nas aulas, e no ano de 1948 organizou uma equipe de voleibol para representar o Colégio, destacando-se pelas conquistas em diversos campeonatos. Braga (2006) pontua que o professor se tornou um expoente no esporte do estado, organizando inclusive a primeira competição atlética estudantil de Campo Grande, na inauguração do Estádio Belmar Fidalgo, em 1953 (Braga, 2005, p.70).

Jairo Alves Fontoura é representado por Braga (2006, p. 70) como um profissional de desempenho mais "acanhado" em comparação ao professor Pimentel. Suas manifestações se detinham às cerimônias cívicas tradicionais do Colégio. As apurações de Braga (2006, p. 71) demonstraram que nos anos de 1957, 1958 e 1959, o professor assumiu distintas funções na instituição. A primeira foi de professor de Educação Física, em 1957, por ofício enviado para a direção. A segunda, em 1958, foi registrada na relação de professores, arrolando Jairo como professor de Inglês. Já em 1959, ele acumulou uma terceira ocupação como secretário escolar.

A descrição reforça a concepção da disparidade entre determinações legais maiores, esfera federal, e práticas exercidas em menor âmbito, no caso, estadual e municipal. O que se observa é a absorção máxima de um contingente em diferentes matérias a fim de suplementar, talvez, a falta de candidatos ao cargo.

Braga (2006, p. 72) ressalta ainda que ambos tiveram uma trajetória paralela aos direcionamentos legais determinados por decretos estaduais sobre o devido registro docente. Em junho de 1960, outro episódio peculiar envolvendo o professor Jairo é descrito pelo autor. Naquela ocasião, abriu-se um concurso para professores catedráticos para as disciplinas de Português, Francês, Inglês, Matemática, Ciências Naturais, História Geral, Canto Orfeônico e Educação Física. A inscrição era precedida do critério de apresentação de diploma pela Escola de Educação Física oficial ou oficializada, dentre outros documentos.

Tanto Alcídio Pimentel quanto Jairo Alves Fontoura realizaram suas inscrições, porém o professor Jairo não apresentou seu registro de professor, mesmo já ministrando duas disciplinas. Segundo a apuração de Braga (2006, p.73) nos registros do Colégio, a inscrição do professor Jairo não foi autorizada. Porém seu nome foi incluído entre os inscritos pela direção do Colégio em Ofício de 30 de setembro de 1960 e, em 29 de outubro de 1960, Jairo foi autorizado a lecionar. 
Um outro exemplo singular é o professor Gilberto Gomes Santiago que mesmo sem o registro de autorização junto ao Ministério e com o curso de técnico em Contabilidade e de Educação Física do Exército, assumiu a cadeira de Educação Física em 2 de maio de 1967 (Braga, 2006, p. 155).

Braga (2006, p.74) justifica que a "contradição entre as determinações legais e o movimento interno da escola e dos atores que a compõem, ora acatando as decisões, em outras negando e desvirtuando, [criando] um movimento constante". $\mathrm{O}$ autor conclui que a disciplina de Educação Física implicava na contratação de militares devido ao prestígio que a categoria detinha junto à sociedade, a afinidade entre as práticas na academia militar e os conteúdos da disciplina escolar.

A disciplina de História não se distanciava da realidade até aqui apresentada. As informações apuradas por Menezes (2012, p. 63) demonstram a presença de normalistas licenciados pela CADES, advogados e militares, e nenhum devidamente formado na área de História. $O$ autor afirma que o ingresso dos professores na escola estava sob condição provisória e que, com os cursos da CADES, a estabilidade na carreira estava garantida, uma vez que eles poderiam, por meio da Campanha, obter seu devido registro.

Em entrevista concedida para Maria da Gloria Sá Rosa, no livro Memória da Cultura e da Educação em Mato Grosso do Sul (Rosa, 1990), Maria Constança Barros Machado, que foi professora e diretora do Colégio Estadual, aponta que o professor estava submetido a uma vida:

[...] feita de insegurança: financeira, política e emocional. Entrava-se no magistério através da influência de algum pistolão, mais tarde, se mudava o governo, quem era contra, lia no jornal sua exoneração. Todo mundo era interino - não se falava em concurso de efetivação, nem tampouco de aumento. [...] Em 1948, por questões políticas, fui demitida do meu cargo de diretora do Ginásio Estadual Campo-grandense pelo então governador Arnaldo Estevão de Figueiredo. (Machado citado por Menezes, 2012, p. 62).

Compreende-se que a carreira não se mostrava estável, o que surtia efeitos, possivelmente, na atuação e contratação de professores. Entretanto, na década de 1960, percebeu-se um movimento de estabilidade que se evidenciou pela adoção mais regular de concurso para admissão de professores (Menezes, 2012, p. 62).

O contexto da disciplina de Língua Inglesa é descrito em concordância aos exemplos explicitados, isto é, os professores não possuíam formação superior e acumulavam mais de uma disciplina para lecionar. Grande parte dos docentes "tinham outras profissões e na maioria das vezes, abandonavam as salas de aula em função de suas carreiras [e] exerciam a função de professores sem ter a formação pedagógica e didática para atuarem nas disciplinas que ministravam" (Rahe, 2006, p. 75).

Rahe (2006) traz dois professores que ilustram a disciplina de Língua Inglesa no Colégio Estadual. O primeiro é o professor Nagib Raslan (1950 - 1970), outrora mencionado, formado em Inglês e História pela Universidade Americana de Beirute. Em relatos de ex-alunos presentes no trabalho de Rahe (2006), o professor Nagib é lembrado afetuosamente como uma figura singular e munida de uma didática promotora de aprendizado. 
A segunda em destaque é a professora Rosa Melke (1955 - 1970). Seu ingresso no magistério pode ser classificado como um possível modo de contratação vigente naquele momento. Seu depoimento revela que foi procurada pela então diretora do Colégio Estadual, Maria Constança Barros Machado, para assumir a disciplina de Língua Inglesa em substituição a professora Dorothy Evangelina Lindores.

A escolha da direção foi justificada por Rosa Melke ser considerada uma personalidade com conhecimento e habilidade no idioma norte-americano, visto que foi ensinada por professores particulares desde criança. Após o episódio, a professora Rosa acabou se tornando a primeira professora catedrática da disciplina de Língua Inglesa do novo endereço do Colégio, em 1955. Ela ainda atuava em duas outras instituições: Colégio Osvaldo Cruz e Nossa Senhora Auxiliadora e dividiu a disciplina no Colégio Estadual, a partir de 1967, com o professor Horácio Braga, seminarista que se formou em Letras na instituição Faculdades Unidas Católicas de Mato Grosso (FUCMAT), em 1973.

As amostras supracitadas revelam a incoerência entre realidade e texto legal. As ilegalidades eram vistas tanto na forma de admissão como nos artifícios adotados para preencher o quadro funcional.

\section{Enfim, uma solução? Os cursos da CADES em Campo Grande}

Os cursos da CADES na porção sul do estado ocorreram no Colégio Estadual Campo-grandense nos anos de 1957, 1958 e 1959. O primeiro curso teve seu início no dia 6 de janeiro e encerramento no dia 31 do mesmo mês, aplicado de maneira concentrada e atendendo somente às disciplinas de Português, Francês e Matemática. As funções de Orientador e professor de Didática Geral ficaram sob a responsabilidade de Leodegário Amarante de Azevedo Filho e como Coordenador estava o professor Ernesto Garcia de Araújo. (Livro, 1957).

Cada disciplina contava com duas matérias: Didática Especial e Conteúdo, além da Didática Geral. Na ocasião referida, os professores responsáveis pela ministração do curso eram: Leodegário Amarante de Azevedo Filho (Português), Antônio Rodolpho Moura e Carlos Henrique Schrader (Francês), Luiz Cavallon e Darcy Vieira Mayer (Matemática). Um atributo a ser pontuado é a realização de aulas inaugurais e de encerramento a todos os alunos, geralmente ministradas por nomes ilustres do cenário nacional, acentuando um caráter de solenidade ao acontecimento.

O desígnio do curso era preparar o candidato para o exame de suficiência que ocorria dias após o encerramento daquele. Faz-se oportuno mencionar um registro de abertura de inscrição de exames de suficiência anterior ao primeiro curso da CADES. Mais precisamente, o registro relata que:

Ao primeiro dia do mês de julho do ano de mil novecentos e cinquenta e três (1953), na Secretaria do Colégio Estadual Campograndense [...] foram abertas as inscrições dos candidatos aos Exames de Suficiência, para registro de professores do curso secundário, [...] a realizarem-se neste colégio, no período de seis (6) a dez (10) do corrente mês. (Termos, 1953). 
Contudo, o trecho acima revela um hiato de sete anos entre a imposição dos exames pelo Decreto o․ 8.777, de 22 de janeiro de 1946 e sua, provavelmente, primeira execução na cidade de Campo Grande, em 1953. Inscreveram-se um total de trinta e quatro postulantes de estabelecimentos públicos e privados ${ }^{5}$ : dezesseis de Campo Grande, seis de Ponta Porã, sete de Três Lagoas e cinco de Bela Vista. (Termos, 1953).

Reportando-se ao ano de 1957, os exames foram realizados no dia 4 de fevereiro de 1957 e no dia 8 de fevereiro foram divulgados seus resultados. Foram aprovados 10 alunos mestres ${ }^{6}$. (Livro, 1956-1967).

Iniciando em 5 de janeiro de 1958 e encerrando em 31 de janeiro, o segundo curso da CADES teve como Orientador o professor Manoel Ferreira Lima, com um acréscimo de cinco disciplinas: Inglês, História, Geografia, Desenho e Latim. Em 4 de fevereiro os exames de suficiência foram aplicados, resultando em 54 aprovados, conforme o registro de divulgação em 10 de fevereiro de 1958. (Livro, 1956-1967).

No Livro de Ocorrências encontra-se menção a instalação do terceiro curso da CADES em 5 de janeiro de 1959 sob orientação do professor Carlos Marie Cantão. Sobre seu término, os registros mostram que foi dia 30 de janeiro no Colégio Nossa Senhora Auxiliadora. (Livro, 1956-1967).

A aplicação dos exames de suficiência e a publicação dos resultados se sucederam em 3 e 7 de fevereiro, respectivamente. Dessa vez, foram oferecidos cursos para as disciplinas de Inglês, Matemática, Português, História, Geografia, Física, Ciências Naturais e Desenho. Foram 70 inscritos, destes foram 66 aprovados e 4 reprovados.

O curso ocorreu no Colégio Estadual até o ano de 1960, como explica Oliveira (2009). De acordo com a autora, não foram encontrados mais registros nos livros de ocorrência do Colégio Estadual e nem maiores detalhes, tais como disciplinas, inscritos e aprovados.

Outro fator que pode ser considerado quando se discute a diminuição desses cursos, foi a propagação de instituições superiores pelo território nacional, inclusive em Campo Grande. A exemplo disso, em 1961 foi criada, pela ordem Salesiana, a Faculdade Dom Aquino de Filosofia e Ciências e Letras de Campo Grande, em 24 de novembro daquele ano, por meio do Decreto n.o 217 e o reconhecimento em 23 de dezembro de 1968, pelo Decreto n.ㅇ 63.850 (Rahe, 2006, p.38). Nela seria possível cursar a graduação para atuar no ensino secundário.

\section{Considerações finais}

Retomando a reflexão de Rüsen (2007, p. 104) sobre a investigação histórica a "pesquisa histórica é um processo cognitivo, no qual os dados das fontes são apreendidos e elaborados para concretizar ou modificar empiricamente perspectivas (teóricas) referentes ao passado humano".

Entendemos que foi essa a operação realizada no estudo em questão, nos conduzimos aos registros e documentos do Colégio Estadual Campo-grandense disponíveis digitalmente e nos apropriamos do olhar investigativo conduzido pelos questionamentos sobre a formação, condição e admissão do professorado secundarista. Estabelecemos tal qual um processo cognitivo de apreensão dos dados, 
e por consequência, Ihes atribuímos um significado, resultando no entendimento de um período histórico.

Ainda procedendo conforme a visão de Rüsen, realizamos uma seleção de um corpus material, no acervo de documentos do Colégio Estadual e nas dissertações, observando que houve uma tímida progressão na regularização da formação dos professores da etapa secundária, ao passo que ocorria a expansão do ensino secundário.

Sobre o aspecto da contratação de professores, os relatos trazidos nas dissertações e apontamentos sobre os professores das disciplinas de Inglês, Latim, História, Francês e Educação Física, permitiram constatar que a admissão e os critérios de contratação também não correspondiam à letra da lei. Percebeu-se artifícios de seleção de professores tanto antes, durante, como depois, dos cursos da CADES, que eram feitas pautadas por indicações de terceiros e por conhecimento cultural em detrimento do seu devido registro no Departamento Nacional de Ensino ou diplomação superior.

A realização dos cursos da CADES no Colégio Estadual respondeu tanto à sua própria ocorrência quanto às características profissionais dos docentes. Essa verificação apontou que havia uma intenção de proporcionar uma preparação para os professores que prestavam os exames. A conclusão garantida pela aferição dos dados revelou um aumento da oferta de disciplinas, começando com apenas três, em 1956, e evoluindo para nove, em 1959. No entanto, as condições do corpo docente se alteraram, ainda que minimamente, evidenciando a permanência no quadro funcional de professores não certificados pelos exames e sem licenciatura superior.

Alguns condicionantes puderam atender a compreensão desse cenário. Um deles se refere à dificuldade de se organizar os cursos da CADES, que contavam com a presença de professores renomados nacionalmente para compor a banca de avaliação de cada disciplina, outro fator considerado é a significativa demanda a qual o curso se prestava, posto que os inscritos advinham de outras cidades e instituições.

Logo, a formação dos professores secundaristas apregoada pelas reformas Francisco Campos, em 1931, e Gustavo Capanema, em 1942, mostrou-se, em grande parte, apenas uma norma distante da concretude da realidade educacional matogrossense.

\section{Notas}

\footnotetext{
${ }^{1}$ A pesquisa em questão é "Implantação e expansão do ensino secundário no sul de Mato Grosso (1942-1961)", coordenado por Stella Sanches de Oliveira Silva, Edital UFMS/PROPP, no 30, de 17/02/2017, e está vinculado à pesquisa "Ensino secundário no Brasil em perspectiva histórica e comparada (1942-1961)", financiada pelo CNPq (Edital Universal 01/2016 - Faixa B), coordenado por Eurize Caldas Pessanha, Universidade Federal da Grande Dourados.

2 Colégio Santa Tereza (1899); Colégio Imaculada Conceição (1904); Instituto Pestalozzi (1915); Colégio Dom Bosco (1917); Colégio Nossa Senhora Auxiliadora (1926); Colégio Oswaldo Cruz (1927); Colégio Estadual Maria Leite (1937) e; Colégio Maria Constança de Barros Machado (1937).

${ }^{3}$ Colégio Estadual Cândido Mariano (1944); Colégio Estadual Três de Julho (194?); Ginásio Rio Branco (1949); Ginásio Estadual de Bela Vista (1950); Colégio Estadual Presidente Vargas (1951); Ginásio Wladislau Garcia Gomes (1951); Ginásio Oswaldo Cruz (1954); Ginásio Guia Lopes (1959) e; Ginásio Estadual de Maracaju (1959).

${ }^{4}$ Nicolau Fragelli; João Calixto; Maria Constança de Barros Machado; Edna Albuquerque; Anna Luiza Prado Bastos; Glauco Rodrigues Correa; Alexandre do Espírito Santo; Claudio Guiseppe Furlanetto; Valeska Perez; Therezinha Oliveira; Eza Leite; Marly Proença Teixeira.

${ }^{5}$ Ginásio São Francisco de Assis (Ponta Porã); Ginásio Estadual Dois de Julho e Escola Normal Dom
} 
Aquino Corrêa (Três Lagoas); Ginásio Barão do Rio Branco, Colégio Dom Bosco, Colégio Estadual Campograndense e Colégio Oswaldo Cruz (Campo Grande) e; Ginásio Bela Vista (Bela Vista).

${ }^{6}$ Arassuay Gomes de Castro, Dilza Maria da Silva, Fernando de Souza Pereira, Firmo Pinto Duarte Filho e Ruy de Souza Cunha (Português); Dirce Nunes Costa (Francês); Djalma Miguel de Menezes, Geraldo Bimmermann, João Vicinanza, Paulo Eugenio Pinto Guedes (Matemática).

\section{Referências}

Adimari, M. F. (2005). Escola e Cidade: Os sentidos dos espaços no Maria Constança, Campo Grande/MS (1954-2004) - (Dissertação de Mestrado) - Universidade Federal de Mato Grosso do Sul, Campo Grande.

Amado, Gildásio. (1973). Educação média e fundamental. Rio de Janeiro: José Olympio.

Backes, T., \& Gaertner, R., (2007). Educação e memória: inventário das obras publicadas na área de matemática pela campanha de aperfeiçoamento e difusão do ensino secundário (CADES). Dynamis Revista Tecno-Científica, (13), 21-28.

Baraldi, I. M. (2016). CADES e a Formação de Professores para o Ensino Secundário: uma campanha nos anos de 1950-1960. In: 3o Encontro Nacional de Pesquisa em História da Educação Matemática (p. 43). São Mateus, SP.

Braga, H. S. (2005). O Ensino de Latim na Escola Maria Constança Barros Machado como Reflexo da História da Disciplina no Brasil (1939 - 1971). (Dissertação de Mestrado) - Universidade Federal de Mato Grosso do Sul, Campo Grande.

Braga, P. H. A. (2006). A Disciplina Educação Física no Maria Constança: expressões da cultura escolar no período de 1954-1964. Dissertação (Mestrado em Educação) Universidade Federal de Mato Grosso do Sul, Campo Grande.

Brasil. Decreto no 19.890, de 18 de Abril de 1931. Dispõe sobre a organização do Ensino Secundário. Diário Oficial - 1/5/1931, p.6.945.

Brasil. Decreto-Lei no. 4.244, de 9 de abril de 1942. Lei orgânica do ensino secundário. Diário Oficial da União - Seção 1 - 10/4/1942, p.5.798.

Brasil. Decreto no 8.777, de 22 de janeiro de 1946. Dispõe sobre o registro definitivo de professores de ensino secundário no Ministério da Educação e Saúde. Diário Oficial da União - Seção 1 - 24/1/1946, página 1.207.

Brasil. Decreto no 34.638 de 17 de novembro de 1953. Institui a Campanha de Aperfeiçoamento e Difusão do Ensino Secundário. Diário Oficial da União - Seção 1 20/11/1953, p. 19.912.

Brito, S. H. A. Educação e sociedade na fronteira oeste do Brasil: Corumbá (19301954). (2001). (Tese em Doutorado) - Universidade Estadual de Campinas, Campinas.

Brito, S. H. A., \& Silva, S. S. O. (2019). História das Instituições de Ensino Secundário no Sul de Mato Grosso (1942-1961): Primeiras Aproximações. In: Castro, C. A. (org.). Ensino secundário no Brasil: perspectivas históricas (p. 351 -356). São Luís, MA: EDUFMA.

Cadastro geral dos professores registrados. (1957). Livro Cadastro geral dos professores registrados.

Decreto, de 25 de abril de 1945. Livro Registro de Correspondências Recebidas, 1945/1951. 
Escola Secundária. (1957). Revista Escola Secundária. Rio de Janeiro, (1), 5-9.

Ferreira, V. L., \& Santos, V. M. (2007). Contribuições ao Estudo da Construção da Metodologia do Ensino de Matemática como Disciplina Escolar no Brasil. In: IX Congresso Estadual Paulista sobre Formação de Educadores, (p. 81). São Paulo, SP.

Fonseca, S. A. (2003). A Revista "Escola Secundária" e o programa de professores da CADES. ANPUH - XXII Simpósio Nacional de História, (p. 8). João Pessoa, PB.

Livro de Ocorrências, 1956 - 1967. (2011). In: Pessanha, Eurize Caldas; Assis, Wanderlice da Silva. Arquivos digitalizados da Escola Estadual Maria Constança Barros Machado (Campo Grande/MS). Campo Grande, MS: W. S. Assis, Caixa 8, DVD 4.

Masson, M. A. C. (1993). A Cades e a qualificação do magistério: notas para compreensão sociológica de uma campanha educacional no Brasil dos 50/60. Rio de Janeiro, RJ. (Arquivo Cades. UFRJ/Proedes).

Menezes, F. V. (2012). Indícios das Práticas Curriculares na Disciplina História em uma Escola Exemplar de Campo Grande entre 1942 e 1970. (Dissertação de Mestrado) - Universidade Federal de Mato Grosso do Sul, Campo Grande.

Miranda, B. C. B. (2019). A CADES e um novo modelo de professor secundário nas décadas de 1950 e 1960. (Tese de Doutorado) - Universidade Estadual Paulista Júlio de Mesquita Filho, Rio Claro.

Oliveira, S. S. (2009). A História da Disciplina Escolar Francês no Colégio Estadual Campo-Grandense - (1942 - 1962). (Dissertação de Mestrado) - Universidade Federal de Mato Grosso do Sul, Campo Grande.

Pinto, D. C. (2008). Campanha de Aperfeiçoamento e Difusão do Ensino Secundário: uma trajetória bem-sucedida?. In: Mendonça, A. W., \& Xavier, L. N. (Orgs.). Por uma política de formação do magistério nacional: o Inep/MEC dos anos 1950/1960. Brasília: Instituto Nacional de Estudos e Pesquisas Educacionais Anísio Teixeira, (p. 145-178). Brasília, DF: Inep.

Rahe, M. B. (2006). A Disciplina Língua Inglesa e o "Sotaque Norte Americano": Uma Investigação das Práticas Docentes no Maria Constança (1955 - 2005). (Dissertação de Mestrado) - Universidade Federal de Mato Grosso do Sul, Campo Grande.

Ribeiro, S. A. (2013). Habitus Estudantil e Distinção no Colégio Maria Constança Barros Machado (1950-1970). (Dissertação de Mestrado) - Universidade Federal de Mato Grosso do Sul, Campo Grande.

Rosa, M. G. S. (1990). Memória da cultura e da educação em Mato Grosso do Sul. Campo Grande: Editora da UFMS.

Rusen, J. (2007). Reconstrução do passado - Teoria da História II: os princípios da pesquisa histórica. Asta-Rose A., \& Estevão, R. M. (trad.). Brasília, DF: UNB.

Termos de inscrição e exames dos candidatos aos exames de suficiência para registro de professores do curso secundário, 1953. (2011). In: Pessanha, Eurize Caldas; Assis, Wanderlice da Silva. Arquivos digitalizados da Escola Estadual Maria Constança Barros Machado (Campo Grande/MS). Campo Grande, MS: W. S. Assis, Caixa 8, DVD 4. 